\title{
Impacts of East Asian summer and winter monsoons on interannual variations of mass concentrations and direct radiative forcing of black carbon over eastern China
}

Yu-Hao Mao et al.

Correspondence to: Yu-Hao Mao (yhmao@ nuist.edu.cn)

The copyright of individual parts of the supplement might differ from the CC-BY 3.0 licence. 
GEOS-4

(a) JJA

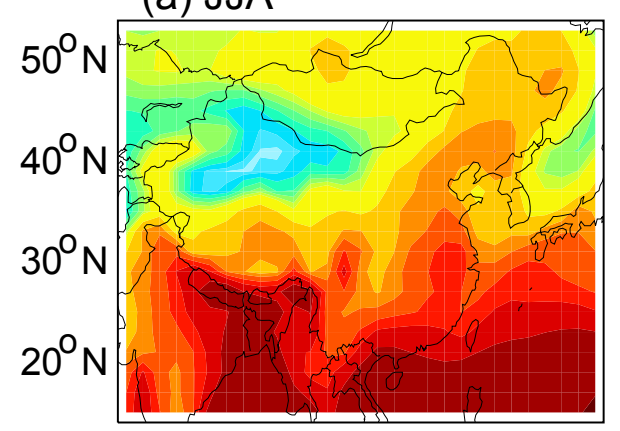

(b) DJF
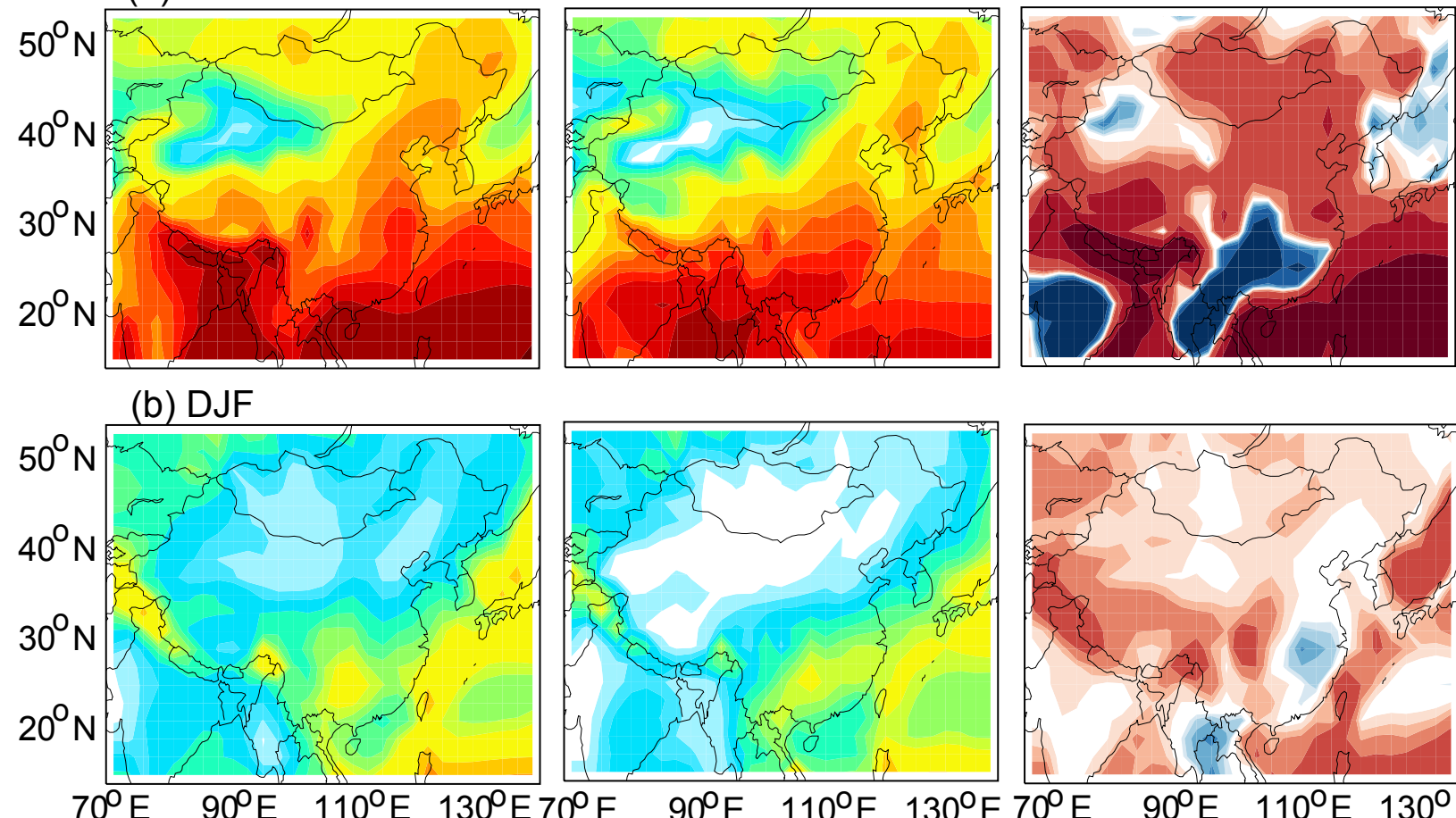

GEOS-4 - MERRA

MERRA
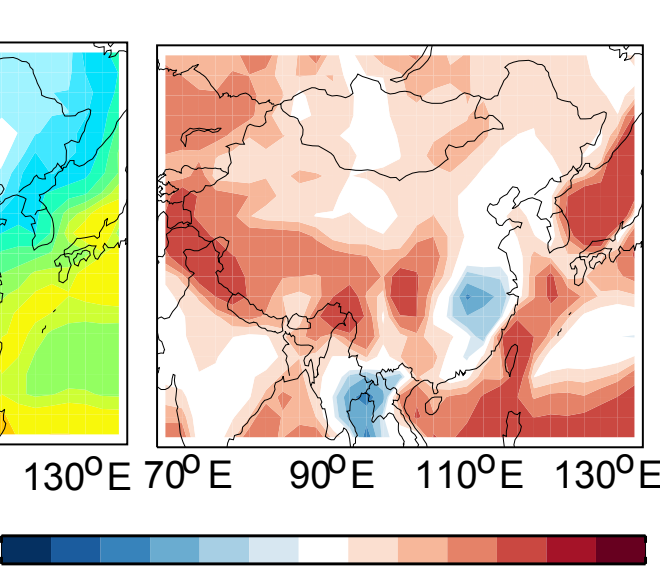

$\begin{array}{llllllllllllllllllllllll}0 & 0.4 & 1 & 2 & 3 & 7 & 12 & 20 & 40 & \mathrm{~mm} \mathrm{~d}^{-1} & -8 & -2 & -1 & -0.4 & -0.1 & 0.2 & 0.6 & 1 & 3 & 6 & 9 & \mathrm{~mm} \mathrm{~d}^{-1}\end{array}$

Fig. S1. JJA and DJF mean precipitation $\left(\mathrm{mm} \mathrm{d}^{-1}\right)$ averaged for 1986-2006 from (a) GEOS-4 and (b) MERRA meteorological data. Also shown are (c) the differences between GEOS-4 and MERRA data. 

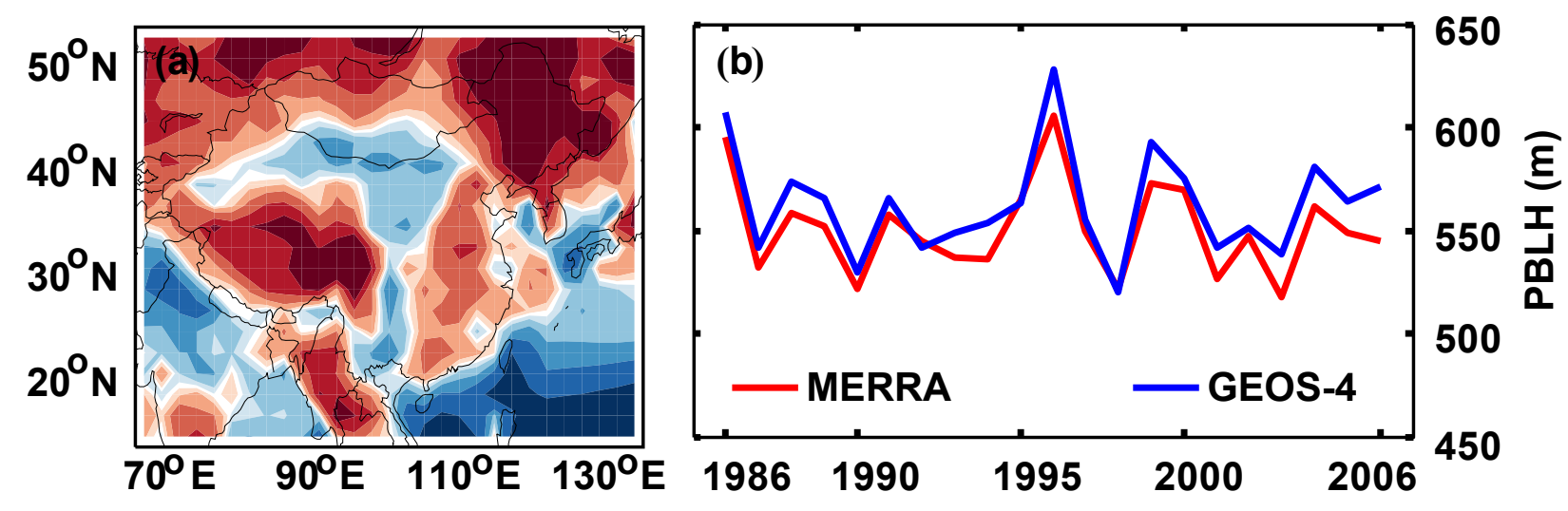

$-500-200-50-20-552050100150200 \mathrm{~m}$

Fig. S2 . (a) Differences in DJF mean planetary boundary layer height (PBLH, m) averaged for 1986-2006 between GEOS-4 and MERRA. (b) DJF mean PBLH averaged over eastern China for 1986-2006 from GEOS-4 (blue line) and MERRA (red line). 